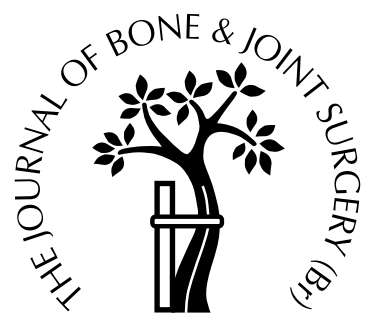

\title{
The prognosis following acute primary glenohumeral dislocation
}

\author{
R. L. te Slaa, M. P. J. M. Wijffels, R. Brand, R. K. Marti \\ From The Reinier de Graaf Groep, Delft, The Netherlands
}

$\mathbf{W}$ have studied 105 patients with 107 acute, primary, dislocations of the glenohumeral joint seen between January 1, 1991 and July 1, 1994. The mean time of follow-up was 71 months (46 to 91). In $34 \%$ the injury occurred during a sports activity and in $\mathbf{2 8 \%}$ at home. The bias toward sport was even greater in patients less than 40 years of age, and in men. In patients older than 40 years of age, and in women, the dislocation occurred more often at home.

The overall probability of recurrence within four years was $26 \%$. Age was the most significant prognostic factor in recurrence which took place in $64 \%$ of patients less than 20 years of age and in $6 \%$ of those older than 40 years. Statistically, there was no difference between the rates of recurrence in patients who were active in sport and those who were not. The mean Rowe score for the whole group was 87 (15 to 100). Associated fractures were found in 20 patients (19\%) and nerve injuries in 22 $(21 \%)$. None of those in whom a fracture of the greater tuberosity was seen subsequently suffered a recurrent dislocation.

At follow-up we found that 36 patients (34\%) had not returned to their former employment but in only $2 \%$ was this owing to the injured shoulder.

J Bone Joint Surg [Br] 2004;86-B:58-64.

Received 16 July 2002; Accepted after revision 5 June 2003
According to Hovelius ${ }^{1,2}$ acute, primary dislocations of the glenohumeral joint occurred in $1.7 \%$ of the general population of Sweden and in $8 \%$ in a selected group of ice-hockey players. Kroner, Lind and Jensen ${ }^{3}$ found an overall incidence of 17/100 000 per year. In the young patient recurrent instability is the most frequent complication. ${ }^{4-11}$ Based on their 'disease specific quality of life scale', Kirkley et al ${ }^{12}$ found a mean reduction of $15 \%$ in shoulder function in patients without a recurrence. Patients older than 40 years of age often have complications other than recurrent instability, such as rupture of the rotator cuff, fracture of the greater tuberosity or nerve injury. The most consistent and significant factor influencing the prognosis of dislocation of the shoulder is the age of the patient at the time of the primary dislocation. $^{4-11}$

We have reviewed a series of 233 dislocations of the glenohumeral joint at our emergency department and report the results of a retrospective study. In this group we analysed the rates of recurrence, the influence of age, sporting activity, complications such as fracture or nerve injury, the time of return to work and any operations required for recurrent instability. We also evaluated the subjective experience of the patients as to whether they still felt confident about using the injured shoulder. We also analysed a small group of patients with bilateral dislocations.

\section{Patients and Methods}

We identified all patients with a glenohumeral dislocation of the shoulder who attended the Emergency Department of the Regional Hospital, Reinier de Graaf Groep, in Delft between January 1, 1991 and July 1, 1994. There were 198 patients with 233 dislocations. Of the total, 133 (131 patients) were primary dislocations and 100 were recurrent injuries (43\%). Of the latter 100, ten patients had already been seen with their first dislocation during the same period. There were 223 anterior dislocations (96\%) and ten were posterior (4\%). They occurred in 154 men and 79 women (ratio 1.95:1). The mean age of the whole group was 39 years (11 to 88). In men the mean age was 32 years (16 to $82)$ and in the women 53 years (11 to 88$)$. The recurrence group (100) had a mean age of 33 years (11 to 76).

The medical records and radiographs of all the patients were studied. At follow-up all patients with a primary dislo- 
cation (131) were evaluated by a telephone questionnaire carried out by the second author (MPJMW); 31 had also participated in a prospective arthroscopic evaluation study of the shoulder. At follow-up the patients were asked about their shoulder function, pain, stability, cause of dislocation, complaints of subluxation, any recurrences, sporting activities, work level, and treatment. The Rowe score ${ }^{13}$ was also recorded.

Of the 131 patients, two had sustained a dislocation of both shoulders $(2.3 \%)$, there were 129 anterior and four posterior dislocations. We excluded the latter from further study. In addition, six patients with six dislocations who had died and 12 patients with 12 dislocations who were lost to follow-up were also excluded. In four cases the answers on the questionnaire were obtained from family members because the patients could not communicate. The present follow-up study therefore includes 105 patients with 107 primary anterior glenohumeral dislocations. The right shoulder was affected in 55 and in 54 the dominant shoulder was involved $(51 \%)$. The mean follow-up was for 71 months (46 to 91 ).

Statistical analysis. The third author (RB) carried out the statistical analysis using SPSS statistics (SPSS Inc, Chicago, Illinois). The unit for analysis was the shoulder, not the patient. Because only two patients had bilateral dislocations, the results were virtually identical to those of an analysis of unilateral dislocations only. The associations between discrete variables are described using cross tabulations and were tested for statistical significance by applying the chi-squared test. Continuous variables were compared between subgroups using the Student's $t$-test or its non-parametric counterpart, the Mann-Whitney $U$ test in the cases of non-normal distributions or outliers. Correlations were tested using Spearman's rank correlation test.

In order to evaluate the relationship between a dichotomous outcome (such as recurrence 'yes' or 'no') and a number of potential risk factors, a logistic regression approach was used. Risk factors were specified in advance and a logistic model was fitted to the data in a backward stepwise approach. Ultimately, only those risk factors were retained which were significantly associated with the probability of the outcome variable under study. The magnitude of the relationship between a predictor and the outcome was quantified by an odds ratio and a corresponding $95 \%$ confidence interval (CI). As a cut-off point for significance, a $\mathrm{p}$ value of 0.05 was used. To show the pattern of recurrence as a function of time elapsed, we computed the probability of recurrence as a function of time using a cumulative incidence approach which, in the absence of censoring until four years, eventually yielded the same point estimate at four years.

\section{Results}

Table I gives details of the recurrent cases with the age at the time of the first dislocation. The mean age of the patients
Table I. Relationship between recurrence and age in patients with glenohumeral dislocation, by number and percentage

\begin{tabular}{lllllllll}
\hline $\begin{array}{l}\text { Number of } \\
\text { recurrences }\end{array}$ & $\begin{array}{l}\text { Total group } \\
(\mathbf{n = 1 0 7 )}\end{array}$ & $\begin{array}{l}\mathbf{2 0} \text { years } \\
(\mathbf{n = 1 4})\end{array}$ & $\begin{array}{l}\text { 20 to 40 } \\
\text { years } \\
(\mathbf{n = 4 3 )}\end{array}$ & $\begin{array}{l}>\text { 40 years } \\
(\mathbf{n}=\mathbf{5 0})\end{array}$ \\
\hline 0 & 79 & 74 & 5 & 36 & 27 & 63 & 47 & 94 \\
1 & 12 & 11 & 4 & 29 & 5 & 12 & 3 & 6 \\
2 & 9 & 8 & 3 & 21 & 6 & 14 & - & - \\
3 & 2 & 2 & 1 & 7 & 1 & 2 & - & - \\
4 & 1 & 1 & - & - & 1 & 2 & - & - \\
5 & 3 & 3 & 1 & 7 & 2 & 5 & - & - \\
$>5$ & 1 & 1 & - & - & 1 & 2 & - & - \\
\hline
\end{tabular}

with a redislocation was 26 years (SD 13), which was significantly different from that of the patients without a recurrence (48 years; SD 20). The overall rate of recurrence was $26 \%$. The age of the patient at the time of dislocation was significantly $(\mathrm{p}<0.0001)$ correlated with recurrence. The odds ratio of age in years on the probability of recurrence was 0.91 (95\% CI 0.87 to 0.95 ) implying that on average the risk of recurrence decreased by a factor of $0.91(9 \%)$ per additional year of patient age, at the time of the first dislocation. The recurrence rate in patients less than 20 years of age $(n=14)$ was $64 \%$ and in patients older than 40 years $(\mathrm{n}=50)$ it was $6 \%$. The overall probability of recurrence within four years was $26 \%$. The mean time between the first dislocation and the first recurrence was 21 months (0 to 81); $71 \%$ sustained their recurrence within two years. We added a survival estimate (cumulative incidence) to show how the recurrence depended on the time elapsed (Fig. 1). There was no association between this time interval and the age of the patient ( $p=0.78$; Spearman's rank correlation). We found no association between right and left sides, dominant versus non-dominant sides and chances of recurrence (chi-squared test).

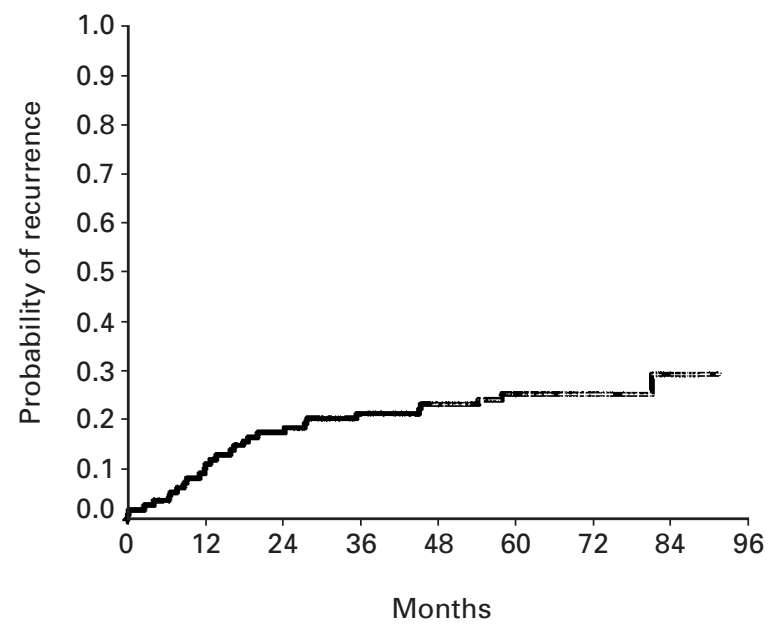

Fig. 1

Cumulative incidence of recurrence of glenohumeral dislocation (probability of dislocation) as a function of number of months elapsed since the primary dislocation. 
Table II. Number of recurrent dislocations, related to gender and age, by number and percentage

\begin{tabular}{|c|c|c|c|c|c|c|c|c|c|c|c|c|}
\hline \multirow{2}{*}{$\begin{array}{l}\text { Number of } \\
\text { recurrences }\end{array}$} & \multicolumn{2}{|c|}{$\begin{array}{l}\text { Men } \\
(n=69)\end{array}$} & \multicolumn{2}{|c|}{$\begin{array}{l}\text { Men } \\
<40 \text { yrs } \\
(n=46)\end{array}$} & \multicolumn{2}{|c|}{$\begin{array}{l}\text { Men } \\
>40 \text { yrs } \\
(n=23)\end{array}$} & \multicolumn{2}{|c|}{$\begin{array}{l}\text { Women } \\
(n=38)\end{array}$} & \multicolumn{2}{|c|}{$\begin{array}{l}\text { Women } \\
<40 \text { yrs } \\
(n=11)\end{array}$} & \multicolumn{2}{|c|}{$\begin{array}{l}\text { Women } \\
>40 \text { yrs } \\
(n=27)\end{array}$} \\
\hline & 49 & 71 & 28 & 61 & 21 & 91 & 30 & 79 & 4 & 36 & 26 & 96 \\
\hline 1 & 10 & 15 & 8 & 17 & 2 & 9 & 2 & 5 & 1 & 9 & 1 & 4 \\
\hline 2 & 6 & 9 & 6 & 13 & - & - & 3 & 8 & 3 & 27 & - & - \\
\hline 3 & 1 & 1 & 1 & 2 & - & - & 1 & 3 & 1 & 9 & - & - \\
\hline 4 & 1 & 1 & 1 & 2 & - & - & - & - & - & - & - & - \\
\hline 5 & 1 & 1 & 1 & 2 & - & - & 2 & 5 & 2 & 18 & - & - \\
\hline$>5$ & 1 & 1 & 1 & 2 & - & - & - & - & - & - & - & - \\
\hline
\end{tabular}

Table III. Cause of first-time dislocations, by number and percentage

\begin{tabular}{|c|c|c|c|c|c|c|c|c|}
\hline \multirow{2}{*}{$\begin{array}{l}\text { Cause } \\
\text { Sport }\end{array}$} & $\begin{array}{l}\text { Total group } \\
(\mathbf{n}=107)\end{array}$ & $\begin{array}{l}\text { Men } \\
(n=69)\end{array}$ & \multicolumn{2}{|c|}{$\begin{array}{l}\text { Women } \\
(\mathbf{n}=\mathbf{3 8})\end{array}$} & \multicolumn{2}{|c|}{$\begin{array}{l}<40 \text { years } \\
(n=57)\end{array}$} & \multicolumn{2}{|c|}{$\begin{array}{l}>40 \text { years } \\
(n=50)\end{array}$} \\
\hline & $36 \quad 34$ & $32 \quad 46$ & 4 & 10.5 & 29 & 51 & 7 & 14 \\
\hline Traffic & $26 \quad 24$ & $\begin{array}{ll}12 \quad 17\end{array}$ & 14 & 37 & 11 & 19 & 15 & 30 \\
\hline Work & $15 \quad 14$ & $14 \quad 20$ & 1 & 2.5 & 8 & 14 & 7 & 14 \\
\hline At home & $30 \quad 28$ & $11 \quad 16$ & 19 & 50 & 9 & 16 & 21 & 42 \\
\hline
\end{tabular}

Table IV. Associated fractures in the patients with glenohumeral dislocation, by number and percentage

\begin{tabular}{|c|c|c|c|c|c|c|}
\hline Fracture & $\begin{array}{l}\text { Total group } \\
(\mathrm{n}=107)\end{array}$ & $\begin{array}{l}\text { Men } \\
(n=69)\end{array}$ & $\begin{array}{l}\text { Women } \\
(\mathbf{n}=\mathbf{3 8})\end{array}$ & $\begin{array}{l}<20 \text { yrs } \\
(n=14)\end{array}$ & $\begin{array}{l}20 \text { to } 40 \mathrm{yrs} \\
(\mathrm{n}=43)\end{array}$ & $\begin{array}{l}>40 \mathrm{yrs} \\
(\mathrm{n}=50)\end{array}$ \\
\hline Number of patients & 8781 & 5681 & 3182 & 14100 & 3684 & $37 \quad 74$ \\
\hline Glenoid & 55 & 46 & 13 & $-\quad-$ & 25 & 36 \\
\hline Greater tuberosity & 1414 & 913 & 616 & $-\quad-$ & 511 & 1020 \\
\hline
\end{tabular}

There were 69 primary dislocations in men and 38 in women (ratio 1.8:1). The sex-ratio differed with age. The recurrence rate, related to gender and age is shown in Table II. Both were multivariably correlated with the probability of recurrence. The estimated odds ratio of recurrence for females compared with males was 3.2 (95\% CI 0.8 to 12 ; $\mathrm{p}=0.08$ ) adjusted for age. There was no significant interaction between age and gender, which implied that the observed difference in the effect of age among males and females was attributed to chance fluctuations. This implied that there was no evidence that the gender effect depended on the actual age. The dislocation occurred during sporting activities in $34 \%$ of the patients (Table III). There was a striking difference in age and gender distribution among the various causes (chi-squared test, $\mathrm{p}<0.01$ ).

We found an associated fracture in 19 patients (18\%) comprising five fractures of the glenoid rim and 14 of the greater tuberosity (Table IV). There were no fractures of the clavicle, acromion, or coracoid process. The incidence of a fracture of the greater tuberosity was clearly influenced by age; the odds ratio for age, in years, on the probability of such a fracture was 1.03 (95\% CI 1.00 to $1.05 ; \mathrm{p}=0.04$ ), implying that the probability increased by $3 \%$ for each year increase of the patient's age from the time of the initial dislocation.

The probability of recurrence was associated with the presence of a fracture of any type. The odds ratio of fracture on recurrence was 0.12 (95\% CI 0.02 to $0.92 ; p=0.04$ ), implying an eightfold reduced probability of recurrence in those patients who sustained a fracture compared with those who had not. We found no fractures in patients under the age of 20 years. The patients who suffered a fracture of the greater tuberosity, none of whom redislocated, had a higher mean age (53 years (21 to 78)) compared with the group without a fracture (mean age 40 years (16 to 84$)$ ) which was not significant; $\mathrm{p}=0.11$.

A nerve injury was found in 22 of the 107 patients $(21 \%)$. This was diagnosed by clinical examination without electrophysiological confirmation. The axillary nerve was injured predominantly $(n=13)$. In patients older than 40 years, 11 of $50(22 \%)$ had a nerve injury compared with 11 of $57(19 \%)$ in patients who were less than 40 years of age. The mean age of the patients with a nerve injury (42 years) did not differ from that in the group without nerve injury. The mean Rowe score differed 4.3 points between those with and without a nerve injury $(\mathrm{p}=0.10)$ and the mean subjective evaluation differed 0.6 points between the same subgroups $(\mathrm{p}=0.96)$.

The mean Rowe score for the whole group was 87 (15 to 100; SD 15.95). There was no significant difference between patients younger and older than 40 years. The mean Rowe score in the recurrence group was 71.9 (55 to 75 ; SD 4.6) and was significantly lower compared with those who did not redislocate and had a mean Rowe score of 92.4 (15 to 100 SD; 15.1). Patients who had confidence in their shoulder had a mean Rowe score of 91.8 (67 to 100; SD 11.5) com- 
Table V. The mean Rowe score in patients with glenohumeral dislocation

\begin{tabular}{|c|c|c|c|c|c|c|c|c|c|c|c|c|c|}
\hline $\begin{array}{l}\text { Rowe } \\
\text { score }\end{array}$ & $\begin{array}{l}\text { Group } \\
(\mathbf{n}=107)\end{array}$ & $\begin{array}{l}\text { Men } \\
(n=69)\end{array}$ & $\begin{array}{l}\text { Women } \\
(\mathbf{n}=38)\end{array}$ & $\begin{array}{l}<40 \mathrm{yrs} \\
(\mathrm{n}=\mathbf{5 7})\end{array}$ & $\begin{array}{l}>40 \mathrm{yrs} \\
(\mathrm{n}=50)\end{array}$ & $\begin{array}{l}\text { No } \\
\text { recurrence } \\
(\mathrm{n}=79)\end{array}$ & $\begin{array}{l}\text { Recurrence } \\
(\mathbf{n}=28)\end{array}$ & $\begin{array}{l}\text { No } \\
\text { confidence } \\
(\mathrm{n}=\mathbf{8 5})\end{array}$ & $\begin{array}{l}\text { Confidence } \\
(\mathrm{n}=22)\end{array}$ & $\begin{array}{l}\text { Fracture } \\
(\mathbf{n}=\mathbf{8 7})\end{array}$ & $\begin{array}{l}\text { No } \\
\text { fracture } \\
(\mathrm{n}=\mathbf{2 0})\end{array}$ & $\begin{array}{l}\text { No nerve } \\
\text { injury } \\
(\mathbf{n}=\mathbf{8 5})\end{array}$ & $\begin{array}{l}\text { Nerve } \\
\text { injury } \\
(\mathrm{n}=22)\end{array}$ \\
\hline $\mathrm{M}$ & 87 & 86.2 & 88 & 84 & 8 & 92.4 & 71 & 91.8 & 68 & 88 & 86.7 & 87.9 & 83.6 \\
\hline Range & 15 to 100 & 15 to 100 & 49 to 100 & 55 to 100 & 15 to 100 & 15 to 100 & 55 to 75 & 67 to 100 & 15 to 100 & 15 to 100 & 49 to 100 & 49 to 100 & 15 to 100 \\
\hline $\mathrm{SD}$ & 15.95 & 17.1 & 13.8 & 14.2 & 17.2 & 15.1 & 4.6 & 11.5 & 17.4 & 21.53 & 14.5 & 14.3 & 21.2 \\
\hline
\end{tabular}

Table VI. Contralateral involvement in patients with glenohumeral dislocation, by number and percentage

\begin{tabular}{|c|c|c|c|c|c|c|c|c|c|c|c|c|}
\hline \multirow{2}{*}{$\begin{array}{l}\begin{array}{l}\text { Other } \\
\text { shoulder }\end{array} \\
\text { Number of patients }\end{array}$} & \multicolumn{2}{|c|}{$\begin{array}{l}\text { Men } \\
(n=69)\end{array}$} & \multicolumn{2}{|c|}{$\begin{array}{l}\text { Men < 40 yrs } \\
(\mathrm{n}=46)\end{array}$} & \multicolumn{2}{|c|}{$\begin{array}{l}\text { Men > 40 yrs } \\
(\mathrm{n}=23)\end{array}$} & \multicolumn{2}{|c|}{$\begin{array}{l}\text { Women } \\
(\mathbf{n}=\mathbf{3 8})\end{array}$} & \multicolumn{2}{|c|}{$\begin{array}{l}\text { Women < } 40 \text { yrs } \\
(\mathrm{n}=11)\end{array}$} & \multicolumn{2}{|c|}{$\begin{array}{l}\text { Women }>40 \text { yrs } \\
(\mathrm{n}=27)\end{array}$} \\
\hline & 54 & 78 & 38 & 83 & 16 & 70 & 30 & 79 & 10 & 91 & 20 & 74 \\
\hline Yes, dislocation & 8 & 12 & 6 & 13 & 2 & 9 & 2 & 5 & 1 & 9 & 1 & 4 \\
\hline Yes pain, no dislocation & 7 & 10 & 2 & 4 & 5 & 22 & 6 & 16 & - & - & 6 & 22 \\
\hline
\end{tabular}

pared with those who lacked it, with a mean score of 68.5 (15 to $100 ;$ SD 17.4). The difference was significant $(\mathrm{p}<0.01)$. Gender showed no significant differences in regard to the Rowe score $(\mathrm{p}=0.50)$, neither did the presence of a fracture of the greater tuberosity or nerve injury ( $\mathrm{p}=0.10$ and 0.32 respectively; Table $\mathrm{V}$ ).

Most of the patients $(n=85)$ felt confident about their shoulder after a primary dislocation despite the fact that 18 of these subsequently dislocated again; 22 did not feel confident about their shoulder at follow-up, but only ten of these had a recurrent dislocation. A visual analogue score (VAS) concerning the patients' satisfaction with their shoulders had a mean value of 8 (2 to 10; SD 1.86). Only 43 of 57 patients under the age of 40 years $(75 \%)$ felt confident about their injured shoulder compared with 42 of $50(80 \%)$ in the older group. Despite the fact that 10 of the 28 patients (36\%) with a recurrence did not feel confident about their injured shoulder, $22(79 \%)$ gave a VAS score of more than six. In the group without recurrence, 12 of 79 did not feel confident about their injured shoulder and 72 (91\%) scored a VAS of more than six. The mean age of those who had confidence in their shoulder was 43 (17 to 84: SD 21.4), whereas the mean age of the others was 39 (16 to 76 ; SD 19.5). The difference, however, is not statistically significant $(\mathrm{p}=0.38)$ or clinically relevant.

During our study, two patients dislocated both shoulders. Furthermore, at follow-up, 23 patients complained about the other shoulder. The complaints were owing to the dislocation in ten patients and to pain without instability in 13 . There was no significant difference between men and women (chi-squared test, $\mathrm{p}=0.42$ ). There was, however, a difference related to age, because five of 23 men (22\%) older than 40 years complained of pain without instability, whereas in those aged less than 40 years only two of 46 (4\%) complained about pain without instability. The same differences were found in women (Table VI). A logistic regression relating the probability of complaints of the other shoulder to both age and gender failed to provide evidence of an interaction in their mutual effect on the outcome (age, $p=0.29$; gender, $p=0.54)$. The mean Rowe score was 81
(65 to 100; SD 11.6) for the ten patients with bilateral dislocation. The mean age of this group of patients with bilateral dislocation was 33 years (18 to 64; SD 16.78). There were eight men and two women, in half of whom there was a recurrence. Six of the ten patients felt confident about their shoulder. The score for subjective evaluation was 7.3 (4.5 to 10; SD 2.12).

At follow-up, 65 patients had been treated conservatively, although it should be borne in mind that 31 of the 107 shoulders had participated in an independent, prospective, arthroscopic study. However, 14 had been operated on, in seven of whom this was to repair a Bankart lesion. The mean age of these seven patients was 27 years (19 to 42). Three were operated on because of disorders of the rotator cuff and four underwent an arthroscopic procedure, without the study protocol.

Sixty-four patients took no part in sport on a regular basis. The mean age in the group with a sporting hobby was lower than in those without (35 years $v 47$ years; SD $16 v 23$; range 17 to 72,17 to 84 : $t$-test, $\mathrm{p}<0.03)$. Soccer was the most common sport to cause a glenohumeral dislocation. The group of patients active in sports had no statistically different rate of recurrence compared with patients not active in sports (chi-squared test; $\mathrm{p}=0.5$ ). The probability of recurrence among the non-sportsmen was $23 \%(n=15)$ and among the sportsmen $30 \%(n=13)$; this association was not significant ( $\mathrm{p}=0.5$; chi-squared test). At follow-up, $60 \%$ of the total group of patients did not return to their previous sport, in $11 \%$ because of symptoms from their shoulder (Table VII). When we looked at sport only as a variable we found that sport was associated with recurrence. However, in the multivariate analysis, we corrected our data with age and subsequently found that there was no prognostic factor with regard to sports participation; only the age factor appeared to have an influence.

At follow-up, 36 of the 107 patients (34\%) did not return to their former employment; in only $2 \%$ because of the injured shoulder and in $32 \%$ for other reasons (Table VIII). We compared patients less than 40 years of age with those older than 40 years and found a significant difference 
Table VII. Patients returning to sport, by number and percentage

\begin{tabular}{|c|c|c|c|}
\hline & $\begin{array}{l}\text { No return to } \\
\text { sport }\end{array}$ & & $\begin{array}{l}\text { Return to } \\
\text { sport }\end{array}$ \\
\hline Total group $(\mathrm{n}=107)$ & 6460 & Total group $(\mathrm{n}=107)$ & $43 \quad 40$ \\
\hline $\begin{array}{l}\text { Because of shoulder } \\
\text { symptoms }\end{array}$ & 1211 & Same/higher level & $31 \quad 29$ \\
\hline $\begin{array}{l}\text { Because of other } \\
\text { reasons }\end{array}$ & 5249 & Lower level & 1211 \\
\hline $\begin{array}{l}\text { Patients with one or } \\
\text { more recurrence } \\
(\mathrm{n}=28)\end{array}$ & $15 \quad 53$ & $\begin{array}{l}\text { Patients with one or } \\
\text { more recurrence } \\
(\mathrm{n}=28)\end{array}$ & 1347 \\
\hline $\begin{array}{l}\text { Because of shoulder } \\
\text { symptoms }\end{array}$ & $4 \quad 14$ & Same/higher level & 933 \\
\hline $\begin{array}{l}\text { Because of other } \\
\text { reasons }\end{array}$ & 1139 & Lower level & $4 \quad 14$ \\
\hline
\end{tabular}

Table VIII. Work activity at follow-up related to age, gender and recurrence, by number and percentage

\begin{tabular}{|c|c|c|c|c|c|c|c|c|c|c|c|c|c|c|}
\hline \multirow{2}{*}{$\frac{\text { Work* }}{\text { No Shou + }}$} & \multicolumn{2}{|c|}{$\begin{array}{l}\text { Whole group } \\
(\mathbf{n}=107)\end{array}$} & \multicolumn{2}{|c|}{$\begin{array}{l}\text { Men } \\
(n=69)\end{array}$} & \multicolumn{2}{|c|}{$\begin{array}{l}\text { Women } \\
(\mathbf{n}=38)\end{array}$} & \multicolumn{2}{|c|}{$\begin{array}{l}<40 \text { yrs } \\
(\mathrm{n}=57)\end{array}$} & \multicolumn{2}{|c|}{$\begin{array}{l}>40 \text { yrs } \\
(\mathrm{n}=50)\end{array}$} & \multicolumn{2}{|c|}{$\begin{array}{l}\text { No recurrence } \\
(\mathbf{n}=79)\end{array}$} & \multicolumn{2}{|c|}{$\begin{array}{l}\text { Recurrence } \\
(\mathbf{n}=\mathbf{2 8})\end{array}$} \\
\hline & 2 & 2 & 1 & 1 & 1 & 3 & - & - & 2 & 4 & 2 & 3 & - & - \\
\hline No Shou - & 34 & 32 & 11 & 16 & 23 & 61 & 1 & 2 & 33 & 66 & 32 & 41 & 2 & 7 \\
\hline Yes Shou = & 54 & 51 & 41 & 59 & 13 & 34 & 41 & 72 & 13 & 26 & 37 & 47 & 17 & 61 \\
\hline Yes Shou + & 3 & 3 & 3 & 4 & - & - & 2 & 4 & 1 & 2 & 1 & 1 & 2 & 7 \\
\hline Yes Shou - & 14 & 13 & 13 & 19 & 1 & 3 & 13 & 23 & 1 & 2 & 7 & 9 & 7 & 25 \\
\hline
\end{tabular}

* No Shou + no work, related to symptoms from the affected shoulder; No Shou - no work, unrelated to symptoms from the affected shoulder; Yes Shou = same work as before shoulder dislocation; Yes Shou + other work because of symptoms from the affected shoulder; Yes Shou - other work unrelated to symptoms from the affected shoulder

(Fisher's exact test; $\mathrm{p}<0.001$ ) with regard to returning to work after recovering from a shoulder dislocation $(98 \% v$ $30 \%)$. The reason for this difference may simply be the age factor since only two of the 50 patients older than 40 years claimed that they could not resume their former work because of the shoulder dislocation. We entered age at injury, sport, gender and dominant shoulder into the logistic model. Patients less than 40 years of age, those with recurrences and men resumed work without problems. In the last two groups this was probably also due to the mean age at the time of dislocation being relatively low.

The probability of resuming work decreased with increasing age (odds ratio: $0.84 ; 95 \%$ CI 0.78 to 0.90 ; $\mathrm{p}<0.01$ ) indicating a decrease of $16 \%$ in probability with each additional year of age; and an eightfold decreased probability when the dominant shoulder was involved (odds ratio $=0.125 ; 95 \%$ CI 0.21 to $0.75 ; p=0.02$ ). As usual, the odds ratios were adjusted for each other's effects.

\section{Discussion}

Nordqvist and Peterson ${ }^{14}$ studied injuries to the shoulder girdle in an urban population and found that dislocations in the elderly group (> 65 years) were owing to falls in $83 \%$ and were accompanied by concomitant lesions in $25 \%$. In adults, $35 \%$ of the glenohumeral dislocations were sustained during sport, as were $34 \%$ of our cases. We found that $57 \%$ of all glenohumeral dislocations which were seen at our emergency department had occurred for the first time.
This is different from the $79 \%$ described in earlier reports by Kazár and Relovsky ${ }^{15}$ and Rowe. ${ }^{9}$ The latter found that the incidence of glenohumeral dislocations before and after the age of 45 was equal. In our study the median age was 36 years. Furthermore, we found that $22 \%$ of the dislocations occurred in patients older than 60 years.

In reviewing the literature we found an overall rate of recurrence ranging between $17 \%$ and $96 \%$ with a mean of $67 \% .^{4,7-12,16-22}$ Several factors, such as age, athletic participation, length of immobilisation, rehabilitation, and length of time spent before returning to sport, are said to have an effect on the rate of recurrence. Age at the time of the first dislocation was the most important prognostic factor for recurrent instability. ${ }^{4-11}$ The study by Hovelius et $\mathrm{al}^{7}$ is currently the only study of the 'natural history' of the condition with follow-up for 2, 5 and 10 years. In the group of patients less than 22 years of age they also found a high rate of recurrence (62\% to $70 \%)$, but only one-third of these recurrent dislocations required a stabilisation operation. We observed an overall probability of recurrence within four years to be $26 \%$. For patients less than 20 years of age this was $64 \%$. In our series, $71 \%$ of the patients had their first recurrence within two years and $82 \%$ within three years. These findings are not consistent with those in other reports.

Some authors found that athletic participation had a significant role in causing glenohumeral dislocations as well as in recurrences. ${ }^{10,22}$ This had already been observed by Bankart $^{23}$ in 1923, who described recurrent dislocation of the shoulder as a "condition peculiar to athletes and epileptics". 
Table IX. Recurrent dislocation of the shoulder related to left and right side and dominance of the arm of the shoulder, by number and percentage

\begin{tabular}{|c|c|c|c|c|}
\hline \multirow[b]{2}{*}{ Recurrence } & \multirow{2}{*}{$\begin{array}{l}\text { Shoulder } \\
\mathbf{R}\end{array}$} & \multirow{2}{*}{$\begin{array}{l}\text { Shoulder } \\
\text { L }\end{array}$} & \multicolumn{2}{|c|}{ Dominant Shoulder } \\
\hline & & & Yes & No \\
\hline No $(n=79)$ & $42 \quad 76.4$ & $37 \quad 71.2$ & $40 \quad 74.1$ & 3973.6 \\
\hline Yes $(n=28)$ & 1323.6 & $15 \quad 28.8$ & $14 \quad 25.9$ & $14 \quad 26.4$ \\
\hline
\end{tabular}

Simonet and Cofield ${ }^{10}$ showed a difference in recurrence rates between athletes and non-athletes. There was a recurrence rate of $82 \%$ in the athletes compared with only $30 \%$ in the non-athletes. Wheeler et $\mathrm{al}^{20}$ found high recurrence rates in $85 \%$ of the non-operatively treated patients in a population of highly trained military personnel. By contrast, Hovelius et al, ${ }^{5,7}$ and recently Kralinger et $\mathrm{al}^{24}$ could not find a positive correlation between sporting activity and recurrence. We also found those engaging in sport did not have a statistically different recurrence rate compared with nonsporting patients. The observed odds ratio was 1.4 but the CI was wide (0.6 to 3.4). However, the difference of $82 \% v$ $30 \%$ is equivalent to an odds ratio of $(82 / 18) /(30 / 70)=10.6$ which is far outside the CI in our study (0.6 to 3.4). We conclude that these findings are incompatible. However, we recognise that the last three studies have an ordinary patient population compared with the selected groups of Wheeler et al. ${ }^{20} \mathrm{~A}$ high level of sporting activity and high endurance in their military group produced higher recurrence rates.

We, like others, ${ }^{4-6}$ could not find any significant prognostic differences between dislocations of the left and right shoulder, nor had the dominance of the arm any influence on the recurrence rate (chi-squared test; $p$ value $=0.6$ and 1.0 ) (Table IX).

It should be emphasised that recurrence is not the only complication of shoulder dislocation. Approximately $15 \%$ to $35 \%$ of all glenohumeral dislocations have an associated fracture of the greater tuberosity. ${ }^{4,25-27}$ Of all these patients with such a fracture, none had a recurrence, compared with $32 \%$ of patients without this fracture. The incidence of fractures of the glenoid rim ranged from $5.4 \%$ to $32 \% .{ }^{27,28}$ In our series we found some associated fracture in $19 \%$ of the patients but none in patients less than 20 years of age. There were no fractures of the tuberosity in the patients with a recurrence $(n=28)$ in contrast to fractures of the tuberosity overall $(\mathrm{n}=15)$ in the patients without a recurrence $(\mathrm{n}=79)^{4,8,9,24}$

We found a nerve injury in 22 out of the 107 patients $(21 \%)$. This value is probably underestimated since our evaluation is based upon clinical examination without electrophysiological examination. Most often the axillary nerve was injured. In our group the mean age of the patients with a nerve injury did not significantly differ from the group without $(t$-test; $p$ value $=0.96$ ). We did not find significant differences between the groups with or without a nerve injury as far as Rowe score and subjective experience were concerned $(t$-test, $\mathrm{p}=0.27$ and 0.98 respectively).
We found that 71 of the patients $(66 \%)$ still managed to do their former work. Approximately half of the patients still do the same work and 17 (16\%) performed other work of whom three changed work because of complaints of the shoulder. At follow-up, 36 patients (34\%) had stopped working, but only in two was this because of the injured shoulder. Therefore, only in five shoulders was the injury the reason for ceasing or changing work.

The Rowe score was significantly lower in the recurrent group compared with the non-recurrent group. We found no statistical differences between men and women, age, nerve injury and fracture of the greater tuberosity. In the subjective evaluation 85 patients felt confident about their injured shoulder. The VAS score regarding the satisfaction of their shoulder varied between 2 and 10 with a mean of 8 (SD 1.86). In contrast to recurrence, age did not influence the VAS score or trust in the shoulder.

Like Hovelius et $\mathrm{al}^{7}$ we also found a higher percentage of bilateral dislocation in patients under 40 years of age compared with the group older than 40 years $(12 \% v 6 \%)$. However, our percentage of bilateral dislocations was lower (9\%). The recurrence rate in this group was $50 \%$.

This is higher than the overall recurrence rate of $26 \%$ of the entire study group. Perhaps a genetic predisposition has a role in the instability of this subgroup. No relation was found between the probability of a bilateral dislocation on the one hand, and age, gender and dominance on the other hand (logistic regression; $p$ values $>0.2$ ).

It is generally assumed that prolonged immobilisation after a glenohumeral dislocation does not influence the rate of recurrence. ${ }^{7,24}$ Itoi et $\mathrm{al}^{29,30}$ questioned the position of the shoulder during immobilisation. The need for physiotherapy is also still a matter for debate. ${ }^{19,21}$ Based on our study we were not able to obtain information on the effect of these factors because it was not possible to evaluate them retrospectively.

It is still debated whether patients with glenohumeral dislocation should be operated on and stabilised immediately. Wheeler et $\mathrm{al}^{20}$ and Arciero et al ${ }^{16-18}$ had undertaken immediate stabilisation in their highly trained military group and had excellent results. However, based on our findings, we do not support routine stabilisation in the general population. However, the very young patient with a high level of sporting activity may benefit from primary stabilisation. Further long-term prospective studies are necessary to analyse this more thoroughly.

We would like to thank Professor P. M. Rozing (Orthopaedic Surgeon, LUMC Leiden) for his help with reading and revising the article.

No benefits in any form have been received or will be received from a commercial party related directly or indirectly to the subject of this article.

\section{References}

1. Hovelius L. Shoulder dislocation in Swedish ice hockey players. Am J Sports Med 1978;6:373-7.

2. Hovelius L. Incidence of shoulder dislocation in Sweden. Clin Orthop 1982;166:127-31.

3. Kroner K, Lind T, Jensen J. The epidemiology of shoulder dislocations. Arch Orthop Trauma Surg 1989;10:288-90. 
4. Hoelen MA, Burgers AM, Rozing PM. Prognosis of primary anterior shoulder dislocation in young adults. Arch Orthop Trauma Surg 1990;110:51-4

5. Hovelius L, Lind B, Thorling J. Primary dislocation of the shoulder: factors affecting the two year prognosis. Clin Orthop 1983;176:181-5.

6. Hovelius L. Anterior dislocation of the shoulder in teenagers and young adults: five-year prognosis. J Bone Joint Surg [Am] 1987;69-A:393-9.

7. Hovelius L, Augustini BG, Fredin H, et al. Primary anterior dislocation of the shoulder in young patients: a ten-year prospective study. J Bone Joint Surg [Am] 1996;78-A:1677-84.

8. McLaughlin HL, MacLellan DI. Recurrent anterior dislocation of the shoulder: a comparative study. J Trauma 1967;7:191-201.

9. Rowe CR. Prognosis in dislocations of the shoulder. J Bone Joint Surg [Am] 1956;38-A:957-77.

10. Simonet WT, Cofield RH. Prognosis in anterior shoulder dislocation. Am J Sports Med 1984;12:19-24.

11. Vermeiren J, Handelberg F, Casteleyn PP, Opdecam P. The rate of recurrence of traumatic anterior dislocation of the shoulder: a study of 154 cases and a review of the literature. Int Orthop 1993;17:337-41.

12. Kirkley A, Griffin S, Richards C, Miniaci A, Mohtadi N. Prospective randomized clinical trial comparing the effectiveness of immediate arthroscopic stabilization versus immobilization and rehabilitation in first traumatic anterior dislocations of the shoulder. Arthroscopy 1999;15:507-14

13. Rowe CR. Evaluation of the shoulder. In: Rowe CR. ed. The shoulder. New York: Churchill Livingstone, 1988:631-7.

14. Nordqvist A, Peterson CJ. Incidence and causes of shoulder girdle injuries in an urban population. J Shoulder Elbow Surg 1995;4:107-12.

15. Kazár B, Relovsky E. Prognosis of primary dislocations of the shoulder. Acta Orthop Scand 1966;40:216-24.

16. Arciero RA, Wheeler JH, Ryan JB, McBride JT. Arthroscopic Bankart repair versus non-operative treatment for acute initial anterior shoulder dislocations. Am J Sports Med 1994;22:589-94.

17. Arciero RA, St. Pierre P. Acute shoulder dislocation: indications and techniques for operative management. Clin Sports Med 1995;14:937-53.
18. Arciero RA, Taylor DC. Primary anterior dislocation of the shoulder in young patients: a ten-year follow-up study. J Bone Joint Surg [Am] 1998;80-A:299-300.

19. Aronen JG, Regan K. Decreasing the incidence of recurrence of first time anterior shoulder dislocations with rehabilitation. Am J Sports Med 1984;12:283-91.

20. Wheeler JH, Ryan JB, Arciero RA, Molinari RN. Arthroscopic versus non operative treatment of acute shoulder dislocations in young athletes. Arthroscopy 1989;5:213-7.

21. Yoneda B, Welsh RP, MacIntosh DL. Conservative treatment of shoulder dislocation in young males. J Bone Joint Surg [Br] 1982;64-B: 254-5.

22. Henry JH, Genung JA. Natural history of glenohumeral dislocation: revisited. Am J Sports Med 1982;10:135-7.

23. Bankart ASB. The pathology and treatment of recurrent dislocation of the shoulder joint. Br J Surg 1923;26:23-9.

24. Kralinger FS, Golser K, Wischatta R, Wambacher M, Sperner G. Predicting recurrence after primary anterior shoulder dislocation. Am J Sports Med 2002;30:116-20.

25. Johnson KJR, Bayley JL. Early complications of acute anterior dislocation of the shoulder in the middle-aged and elderly patient. Injury 1982;13:431-4.

26. Slaa te RL, Verburg H, MD, Marti RK. A fracture of the coracoid process, the greater tuberosity and the glenoid rim after an acute first time anterior shoulder dislocation. J Shoulder Elbow Surg 2001;10: 489-93.

27. Visser CPJ. Zenuwletsel bij schouderluxaties en proximale humerusfracturen. Proefschrift Rijksuniversiteit te Leiden, 1998.

28. Bigliani LU, Newton PM, Steinmann SP, Connor PM, McIlveen SJ. Glenoid rim fractures associated with recurrent anterior dislocation of the shoulder. Am J Sports Med 1998;26:41-5.

29. Itoi E, Hatakeyama Y, Urayama M, et al. Position of immobilization after dislocation of the glenohumeral joint: a cadaver study. J Bone Joint Surg [Am] 1999;81-A:385-90.

30. Itoi E, Sashi R, Minagawa $\mathbf{H}$, et al. Position of immobilization after dislocation of the glenohumeral joint. J Bone Joint Surg [Am] 2001; 83-A:661-7. 